Chapter 20

\title{
LITTORAL TRANSPORT IN THE GREAT LAKES
}

\author{
Dr. I. Bajorunas \\ U. S. Lake Survey, Corps of Engineers
}

\section{INTRODUCTION}

The Great Iakes Superior, Michigan, Huron, Erie, and Ontario extend almost to the middle of the North American Continent. With their 95,000 square miles of water surface and their three navigable connections with the Atlantic Ocean and Gulf of Mexico, they affect the well-being of about 40 million people living within their vicinity in Canada and the United states. Possessing a shoreline of 6,600 miles, these waters have been called the fourth coast of the continent along with the Atlantic, Gulf, and Pacific coasts. This paper analyzes one of the many problems of the Great Lakes, the littoral transport problem.

Iittoral transport has been defined as the movement of material along the shore in the littoral zone by waves and currents. The material thus transported is referred to as the littoral drift. The littoral drift originates from the beach material, being picked up by the water and transported along the shore and deposited in another location. Shore erosion, littoral transport, and deposition of drift are all factors in the littoral process.

A knowledge of the littoral process is important for many engineeri] projects including the construction and maintenance of shoreline harbors. The harbor breakwater extending from the shore into deep water forms a littoral barrier, and by stopping the transport action causes the depositio of drift on the updrift side. If the breakwater does not entirely stop the transport, or when the storage area on the updrift side is filled, the drift will bypass the breakwater and fill the dredged navigation channel causing frequent and expensive maintenance dredging. This problem is especially important in the small harbors on the Great Lakes planned every 25 to 30 miles as refuge for fishing and pleasure boats. These harbors have a rather small capacity for littoral drift, and the costs of maintenan dredging of so many entrance channels would be almost prohibitive.

In order to provide data required for the design and economic evaluation of the small refuge harbors on the Great.Lakes, the United States Lake Survey, Corps of Engineers, conducted a study of the best method of estimating the rate of littoral transport along the shores of the Great Iakes. Although much of the data used in this paper was taken from the above study, the views and conclusions stated here do not necessarily reflect those of the Lake Survey. 


\section{LITTORAL TRANSPORT IN THE GREAT LAKES}

\section{DERIVATION OF TRANSPORT EQUATION}

The present knowledge about littoral transport is briefly summarized by Savage, 1959, in the following way: "The mechanics of littoral transport are not precisely known, but it is generally agreed that the major portion of the littoral transport is caused by waves which approach the shore obliquely. Such waves have three main effects. First, before breaking, the waves create oscillatory currents along the bottom which tend to move material alongshore in suspension in the turbulent eddies generated by the interaction of the oscillatory currents and the sand surface of the bottom. Second, during breaking, these waves produce a current along the shore. Beach material placed into suspension by the turbulence of the breaking waves is carried alongshore in this current. Third, during and after breaking, these waves propel a mass of water up the foreshore. This mass of water has an alongshore velocity component, and therefore moves material slantwise up and down the foreshore; the net direction of material movement being alongshore in the direction of the alongshore energy component of the wave."

General agreement stops at the point where littoral transport is a function of waves in respect to their energy. No methods are generally accepted to bring the amount of drift into accord with the wave energy. Therefore a relationship is needed between transport and energy based on theoretical considerations and actual observations. For the purposes of harbor design, statistical data from long period observations are considered adequate to derive this relationship.

The material lying in the littoral zone must be stirred up before it is picked up and transported downdrift. The transport at a point along a straight shore is the summation of material picked up over a distance $D$ updrift of the point.

$$
Q=\int_{0}^{D} P d D
$$

where,

Q is the transport at a point.

$P$ is the pickup updrift of the point per unit length of shore.

$D$ is the distance updrift over which pickup is taking place.

The pickup is a function of the wave energy component perpendicular to the shore while the transport is a function of the component along the shore.

$$
\begin{aligned}
& P_{0}=c E_{0}^{n} \cos \alpha_{0} \\
& Q_{0}=a E_{0}^{n} \sin \alpha_{0}
\end{aligned}
$$




\section{COASTAL ENGINEERING}

where,

$P_{0}$ is the potential pickup when transport is zero.

Q. is the potential transport when pickup is zero.

c, a, $\mathrm{n}$ are constants.

$\mathrm{E}_{0}$ is the deepwater wave energy.

$\alpha_{0}$ is the angle between the wave crests and the shoreline.

Although the wave energy along a straight coastline is the same per unit length of shore, the portion of energy available for pickup of new material will be only what is left from the energy expended in picking up and transporting the material from updrift reaches. Therefore, the pickup at some distance is:

$$
P=c\left(E_{0}^{n}-E^{n}\right) \cos \alpha_{0}
$$

Substituting the energy from (3), the pickup becomes:

$$
P=b \cot \alpha_{0}\left(Q_{0}-Q\right)
$$

where $b=c / a$.

Substituting the pickup $P$ from (5) in (1), the transport is:

$$
Q=\int_{0}^{D}\left(Q_{0}-Q\right) b \cot \alpha_{0} d D
$$

Integrating (6) and using (3) for $Q_{0}$, we derive the transport equation for a straight coastline:

$$
Q=a E_{0}^{n} \sin \alpha_{0}\left[1-e^{-b D \cot \alpha_{0}}\right]
$$

When the coastline is not straight, it can be divided into several straight reaches, and the transport computed reach by reach. At the downdrift end of the first straight reach, the transport is obtained by equation (7), and at the end of each of the subsequent reaches by the equation:

$$
Q_{2}=Q_{1}\left[e^{-b D_{2} \cot \alpha_{0} 2}\right]+a E_{0}^{n} \sin \alpha_{02}\left[1-e^{-b D_{2} \cot \alpha_{0} 2}\right]
$$

where,

Q1 is the transport at the end of the previous reach.

$\alpha_{0} 2$ is the angle between the wave crest and the shoreline of the straight reach being considered, and

$\mathrm{D}_{2}$ is the length of the latter reach.

\section{IITTORAL TRANSPORT OBSERVATIONS}

In deriving the constants $a, b$, and $n$ in the transport equation (7), the observations were used on rate of littoral transport, deepwater wave energy, length and alignment of shore, available shore material, an the material in transport. Other elements affecting the transport, as 
LITTORAL TRANSPORT IN THE GREAT LAKES
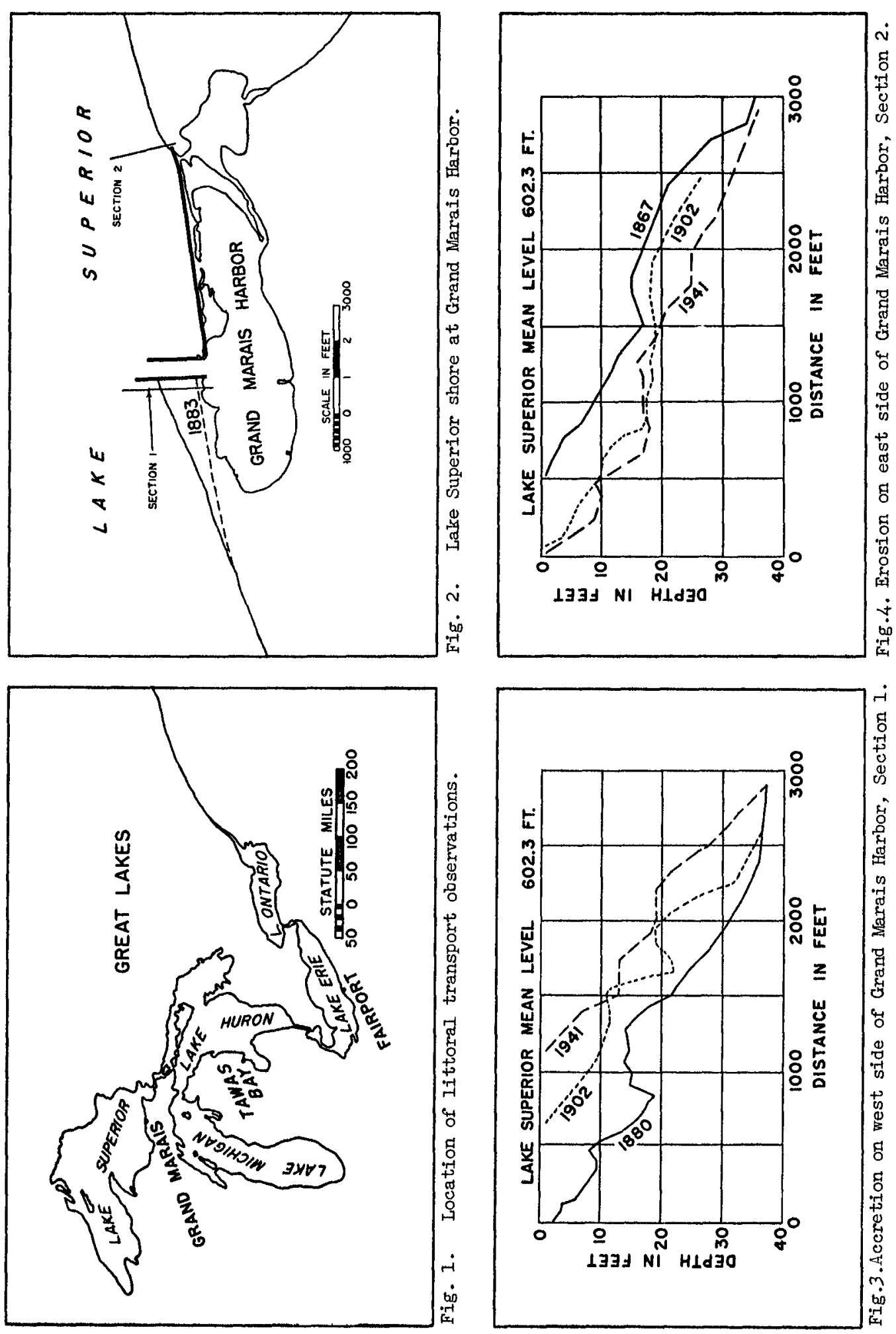
COASTAL ENGINEERING
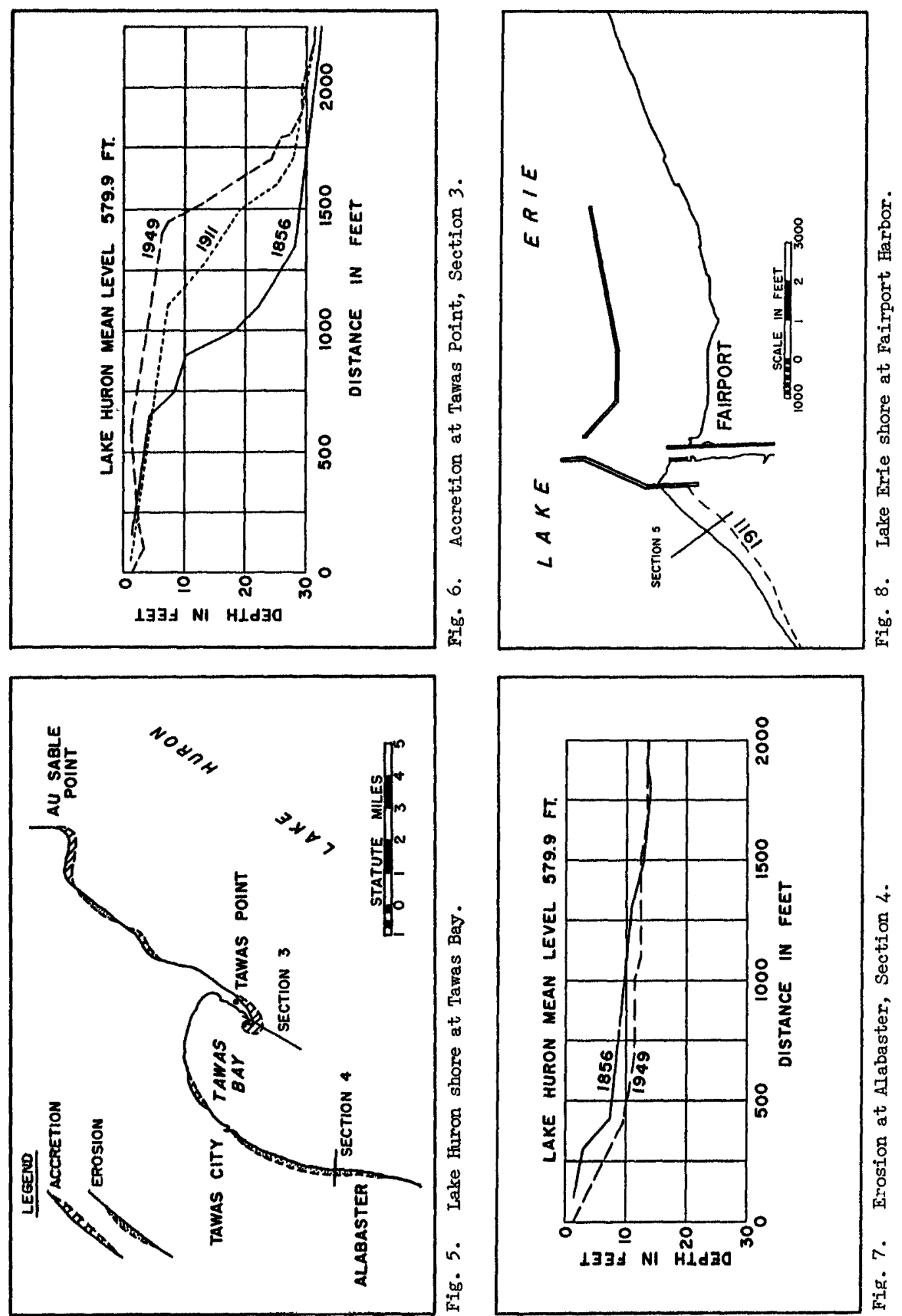


\section{LITTORAL TRANSPORT IN THE GREAT LAKES}

wave steepness, storm duration, wave refraction, lake level, and water temperature, were not considered in the interest of simplifying the problem. They are partly implicit in the statistical data used.

\section{TRANSPORT RATE.}

Remarkably accurate soundings of the offshore and beach areas of the Great Lakes were recorded by the Lake Survey during the last half of the 19th century. These early soundings when compared with more recent hydrographic surveys show the changes along the shore that have taken place over long periods of time. Because even small errors in the soundings or their location along areas of little change result in relatively large inaccuracies in computing the change in volume, the areas to be studied had to be carefully selected. The areas investigated for this study were located at natural or man-made barriers where the changes in volume were large. By catching the transport from one direction and excluding it from the opposite direction, the barriers also made it possible to correlate transport with the wave energy from one direction. Erosion from the relatively short face of the deposited drift is rather small and can be estimated without significant error. The location of the areas selected are shown in Figure 1 , and the results of the detailed investigations are summarized below.

Grand Marais Harbor is located on the southern shore of Lake Superior, see Figure 2. The construction of the harbor was started in 1883 with two parallel breakwaters extending into the lake protecting a dredged navigation channel. Later the breakwaters were extended further into the lake and at the present time are about 2,000 feet long, extending into 20 feet of water. Many hydrographic surveys have been made of the areas on both sides of the harbor, however, most of these surveys did not fully cover the area involved. The soundings made in the vicinity of the harbor in 1880, 1902, and 1941 provided the best data for computing the changes in volume over long periods of time. Profiles from these soundings at Section 1 are shown in Figure 3. The accretion per year on the west side of the harbor was computed as 54,000 cubic yards over the 19-year period from 1883 to 1902 , and 58,000 cubic yards over the 39-year period from 1902 to 1941. The average accretion was 57,000 cubic yards per year for the entire period of 58 years. The rate of erosion from the face of the deposits was estimated to be in the order of 2,000 cubic yards per year. Thus the average transport rate from the west becomes 59,000 cubic yards per year.

The soundings also indicate that a small amount of drift bypasses the west breakwater and is deposited at a depth of about 17 feet. On the east side of the harbor the soundings show a continuous erosion, Figure 4. A protective wall about 5,700 feet long was built along the shore to the east in the 1895-1898 period. The shore material on both sides of the harbor is fine sand, and the supply is unlimited. The deposited material west of the harbor is also fine sand. 
COASTAL ENGINEERING
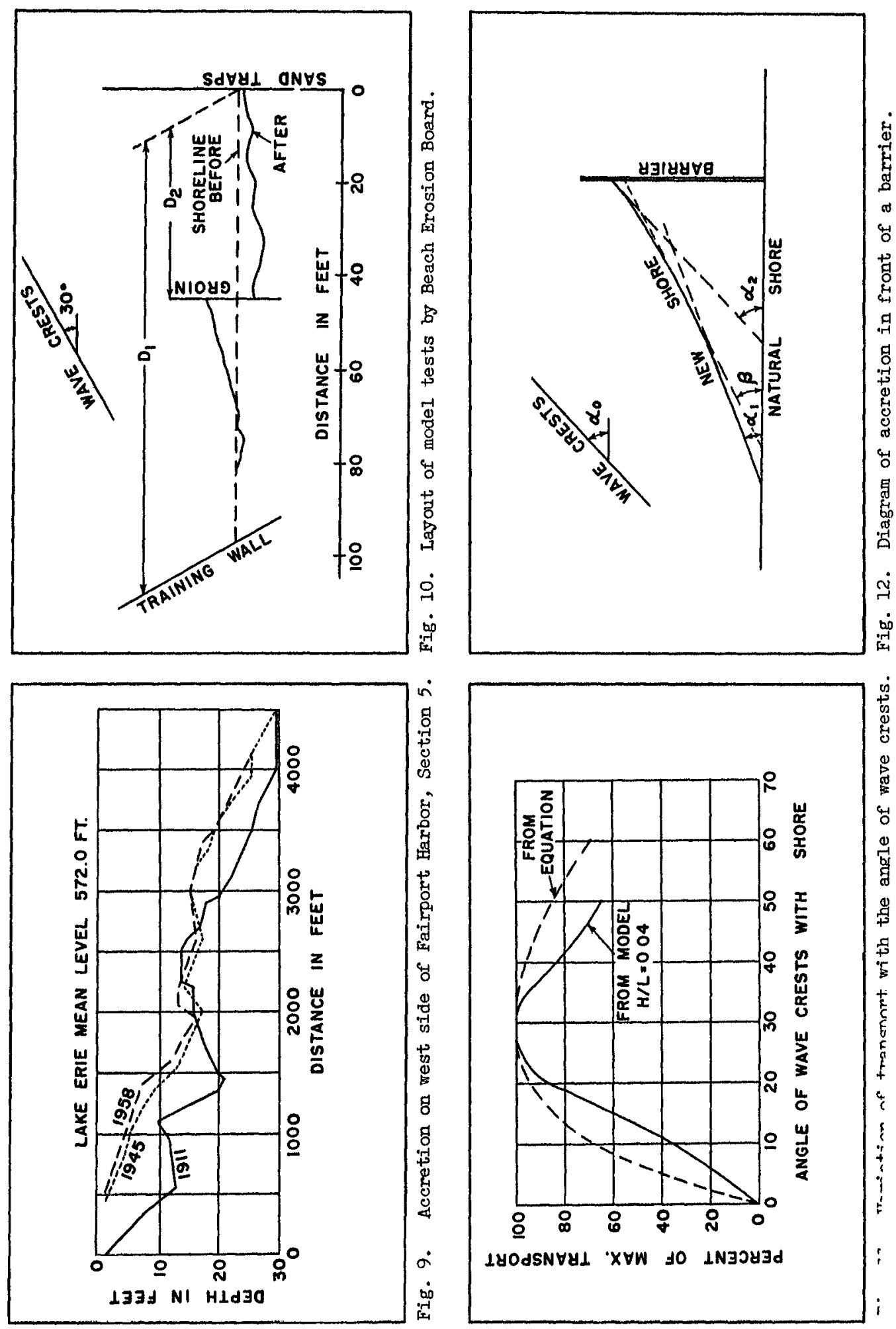


\section{LITTORAL TRANSPORT IN THE GREAT LAKES}

Au Sable Point is about 8 miles northeast of Tawas Point on the west shore of Lake Furon, see Figure 5. The coastline north of Tawas Point has a general northeasterly direction. At Au Sable Point the shore turns sharply to the east and then to the north forming a small bay south of the point. A part of the material being transported from the north is deposited just south of Au Sable Point while the rest of the drift is transported along the shore to be deposited at Tawas Point. Based on the soundings made in 1856 and 1949, the transport at $\mathrm{Au}$ Sable from the north was determined to be 121,000 cubic yards per year. The drift along this reach is sand, and the available beach material north of Au Sable Point is mainly sand with some rock outcrops.

Tawas Point is located on the westerly shore of Lake Furon at Tawas City, Michigan. The contour of the lake shore at this location is such that all the transport is trapped in the Tawas Bay. Most of the material transported along this shore comes from the north and is deposited at the end of Tawas Point. There is a small amount of transport from the south which is deposited at Tawas City.

The accretion at Tawas Point is composed of sand with a rather flat initial slope of 1 on 170. At a depth of about seven feet, the slope abruptly changes to about 1 on 25 , and is more or less constant until the lake bottom is reached in about 30 feet of water. This changing slope is shown by the profiles in Figure 6. The soundings made in 1856 and 1911 indicate that the average accretion at Tawas Point was 67,000 cubic yards per year. The soundings in 1949 show an average accretion of 60,000 cubic yards per year for the period after 1911. The average for the 93-year period was 64,000 cubic yards per year. The accretion at Tawas City is in the order of 2,400 cubic yards per year.

Alabaster is a small town on the shore of Lake Huron about 5 miles south of Tawas City. The lake shore north of Alabaster shows evidence of considerable erosion over the years. It is here where the Lake Huron waves start to pick up new shore material after depositing the transport from the north at Tawas Point. The erosion at Section 4 near Alabaster is shown by the 1856 and 1949 profiles in Figure 7. Over the 93-year period, the erosion in the northerly mile of the reach shown in Figure 5 averaged 4,200 cubic yards per year while the average rate of erosion over the 5-mile reach was 25,000 cubic yards per year. These erosion values are not as accurate as the accretion values obtained because of the relatively large area affected with respect to the amount. The available beach material consists primarily of sand with rocks, clay and occasional gravel scattered throughout the reach.

Fairport Harbor is located near the middle of the southern shore of Lake Erie about 29 miles east of Cleveland. The breakwaters shown in the harbor layout, Figure 8, extend out from the shore into 20 feet of water. The dominant direction of transport in this area is from the west. In Figure 9 the profiles at Section 5 west of the harbor are based on soundings made in 1911, 1945, and 1958. These soundings indicate an accretion during the 1911-45 period of 124,000 cubic yards per year, and during the 1945-58 period 


\section{COASTAL ENGINEERING}

of 88,000 cubic yards per year. The large difference in accretion rates for the two periods may be due to shore construction west of the harbor, such as the water intake pier near the Chagrin River built in 1951, or to an increase in the transport passing the harbor. The erosion from the face of the deposits is estimated to be 6,000 cubic yards per year. On the east side of the harbor a serious erosion problem existed. In 1932 the east breakwater was extended 5,400 feet eastward parallel to the shore to protect the beach.

The Division of Shore Erosion, State of Ohio, made an extensive survey of the beach along the Lake Erie shore. In the reach from Cleveland to Fairport, samples were mostly sand ranging from fine to coarse with the sizes 0.2 to $0.4 \mathrm{~mm}$ predominant. The samples also included some clay, pebbles, and cobblestones. The material deposited on the west side of the harbor is very uniform and has a median size of $0.24 \mathrm{~mm}$ with a coefficient of sorting 1.1. This uniformity of size indicates that waves select the material being transported from the large assortment available on shore.

WAVE ENERGY.

Wave energy is the prime factor of littoral transport. The general circulatory currents and the currents resulting from water level

disturbances do not significantly change the picture of the energy in the littoral zone of the Great Lakes. These currents might be a factor in some isolated restricted areas.

Wave energy for this study was computed by the generally accepted simplified equation for the energy of deepwater waves in fresh water:

$$
E_{0}=20 \mathrm{H}_{0}^{2} \mathrm{~T} t
$$

where,

$E_{0}$ is the annual wave energy transmitted forward from deep water toward the shore in foot-pounds per foot of wave crest.

$\mathrm{H}_{0}$ is the deepwat'er wave height in feet.

$T$ is the wave period in seconds.

$t$ is the time, in seconds, during one year that waves are acting upon the shore from given direction.

Wave height and period.

The height and period of waves are the basic elements used to compute the wave energy. Primarily, these elements depend on the speed of the wind over the water, the fetch over which it blows, and its duration The graphical relationships between winds and waves prepared by Bretschneid and published by the Beach Erosion Board, 1954, were used to obtain the wav heights and periods for significant waves. A significant wave is the avera of the higher one-third of all the waves. The use of significant waves 


\section{LITTORAL TRANSPORT IN THE GREAT LAKES}

results in a wave energy greater than actual. However, the ratio of the actual energy contained in a given wave train to that computed from the significant waves has been found by various authorities to be nearly constant, and in the order of 0.58 . Therefore, the use of significant waves will indicate correctly the variation of the actual wave energy.

Wind speed. Wind statistics for land stations in the vicinity of the sites studied are available for seven to ten year periods. The data listed on IBM cards produced a tabulation of the duration of all winds from 16 different directions for speeds 0-12 mph and 13-24 mph, and of the individual wind speeds of $25 \mathrm{mph}$ and higher. Wind speeds over large water areas are known to be significantly higher than those indicated at adjacent land stations. On Lake superior some wind records are available for the small rocky island, Stannard Rock, 30 miles from the nearest shore. These records may be considered as those of the actual winds over Lake Superior. These overwater winds were found to be about 80 per cent faster than those recorded at the nearest land station. More detailed investigations of the relationship of overwater to overland winds in Lake Erie have been made by Hunt, 1958, using wind observations on commercial vessels equipped with anemometers and at the nearest land stations. The Lake Erie investigations showed the relationship depends upon the stability of the air masses of the overwater area and upon the heights of the anemometers above the land and water surfaces. Based on these findings, the wind speeds from the land stations were adjusted to speeds over the water at an 8 meter level before they were used in wave height and period computations.

Storm duration. From the data available, it was not possible to compute the duration for individual storms with wind speeds less than $25 \mathrm{mph}$. Therefore, it was assumed that these lesser storms lasted long enough to produce waves of ultimate height. The duration of the winds of $25 \mathrm{mph}$ and over was studied in detail and the average values were used to determine the energy.

Fetches were determined from Lake Survey navigation charts for the sites where transport was studied.

Ice effect.

This factor must be considered in estimating the total time the waves act upon the shore. The presence of ice along the shore protects the beach from attack by the waves. The fresh water of the Great Lakes tends to freeze quite early in the winter season, with ice appearing first in the calm inlets and bays and later extending out from the shore into the lake. The ice-free part of the lake varies in size depending upon the severity of the winter, however, none of the Great Lakes has been known to completely freeze over. According to Zumberge and Wilson, 1954, the freezing progresses out from the shore in two steps, first forming an ice foot and then an ice cover. Once established the active ice foot, that borders the open lake, protects the shore from the impact of the breaking waves. However, since the ice often contains some sand, some shore erosion is probably still going on, but on a much smaller scale. Navigation season statistics show that ice and cold weather stops navigation 


\section{COASTAL ENGINEERING}

for an average period of 4.5 months on Lake Superior, 3.5 months on Lake Huron, and 3 months at the westerly end of Lake Erie. The period during which the shore receives the most protection from the ice is shorter than the closed navigation season. For this study the time during each year when no wave action occurs on the shore was considered to be 3 months for Lake Superior, 2.5 months for Lake fluron, and 2 months for Lake Erie. More precise determinations of the time of inactivity would require long observations in the field.

EXPONENT FOR ENERGY.

As indicated in equation (7), the transport varies as the deepwate wave energy with exponent $n$. Based on actual observations and on model tests this exponent was selected as being unity. Evaluation of the expone is possible when all the factors affecting transport are constant except the wave energy. Actual observations for one direction of wave approach are difficult to obtain and adjustment of several directions to one introduces some degree of error. The value of the exponent based on actual observations are listed by Caldwell, Watts, and Lee as follows:

$\begin{array}{ll}\text { Anaheim Bay, California } & 1.0 \\ \text { South Lake Worth Inlet, Florida } & 0.9 \\ \text { Fort Sheridan, Lake Michigan, Illinois } & 0.97\end{array}$

The data for California and Florida shows considerable scatter, but the accuracy should be within ten per cent. Fort Sheridan data for Lake Michigan is based on the energy of individual waves uncorrected for wave period variations, and the 0.97 value may be on the low side.

The data obtained by Sauvage and Vincent in France from model test using a sand with 2.6 specific gravity, indicate a value of 1.1 for the energy exponent. Other model tests, as shown by Savage, 1959, indicate a lower value for the exponent, but the data have much more scatter.

\section{GREAT IAKES TRANSPORT EQUATION}

The constants in the equation (7) were determined by substituting the data developed above and solving the simultaneous equations. The resulting transport equation for a straight shore line in the Great Lakes is:

$$
Q=19 E_{0} \sin \alpha_{0}\left[I-e^{-0.023 D \cot \alpha_{0}}\right]
$$

where

Q is the average annual rate of littoral transport in cubic yards at the downdrift end of a straight reach due to waves from one direction.

$E_{0}$ is the annual deepwater wave energy from one direction $i$ millions of foot-pounds per foot of wave crest.

$\alpha_{0}$ is the angle between the shore line and the wave crests which are considered perpendicular to the wind directi

$D$ is the length of the shore in miles between the point of transport and the updrift barrier.

19 and 0.023 are the constants determined from the data. 


\section{LITTORAL TRANSPORT IN THE GREAT LAKES}

Use of equation.

Equation (10) is designed to compute the annual rate of transport over a long period from long-period average wind data of winds from 16 directions. At the sites investigated the littoral drift is fine sand, and the beach material is mainly sand in unlimited supply. The effects of varying lake levels on the transport have been counterbalanced because of the long periods used. Ad justment of the constants would have to be made before equation (10) could be used under conditions other than those discussed above.

Another point to be considered when using the transport equation is that the shore length is limited by the duration of storms and by the speed the drift moves along the shore. When a storm begins and waves start hitting the lake shore, the transport is at first of uniform rate throughout the total length of a straight shore. As the storm continues the drift moves forward and the transport grows in size. However, there is always a point on an infinitely long shore up to which the transport is growing and from which in the downdrift direction the transport is of uniform rate. This distance from the barrier to the point of constant transport is termed the effective shore length. The effective shore length for the prevailing direction of storms in the Great Lakes may be over 50 miles, however, no observations are available to substantiate this figure.

\section{TESTING THE EQJATION}

The transport equation for the Great Lakes was compared with the available observations in nature or in model to assure that results are in good agreement with the observations.

Comparison with Actual Transport.

The observed transport rates are compared with the rates as computed by equation (10) in the table below.

\begin{tabular}{|l|l|c|c|c|c|c|}
\hline \multirow{2}{*}{ Lake } & Location & \multirow{2}{*}{$\begin{array}{c}\text { Period } \\
\text { in Years }\end{array}$} & $\begin{array}{c}\text { Shore Length } \\
\text { in Miles }\end{array}$ & \multicolumn{3}{|c|}{$\begin{array}{c}\text { Annual } \\
\text { in 1000 Cubic Yarsport }\end{array}$} \\
\cline { 4 - 7 } & & & & Type & Actual & Computed \\
\hline Superior & Grand Marais & 58 & 6 & accretion & 59 & 60 \\
Huron & Au Sable Point & 93 & 34 & accretion & 121 & 123 \\
Huron & Tawas Point & 93 & 42 & accretion & 64 & 63 \\
Furon & Alabaster & 93 & 1 & erosion & 4.2 & 3.7 \\
Huron & Alabaster & 93 & 5 & erosion & 25 & 19 \\
Erie & Fairport & 34 & 21 & accretion & 130 & 115 \\
\hline
\end{tabular}

Observations on most effective angle.

The littoral transport rate varies with the angle between the approaching wave erests and the shore. Waves having the same energy produce the highest transport when approaching the shore at a certain angle. This. most effective angle is generally believed to be constant all along the shore. Model tests by Shay and Johnson indicated that wave crests approaching at an angle of $43^{\circ}$ produce the maximum transport. A later study by Johnson, 1955, 


\section{COASTAL ENGINEERING}

indicated a most effective angle of $30^{\circ}$. A widely adopted method of adjusting the wave energy per foot of wave crest to per foot of shore is that developed by the Los Angeles District, Corps of Engineers, where the factor of $\sin 2 \alpha_{0}$ is used. This factor indicates that an angle of $45^{\circ}$ produces the highest transport. Professor Munch-Petersen from his 40-year experience in research of littoral transport along the ocean coasts concluded that the transport is close to its maximum when the original wave (the deepwater wave) moves parallel to the shore (Svendsen, 1950.)

The transport equation derived for the Great Lakes indicates that the most effective angle is not constant but varies with the length of unobstructed shore. For various lengths of shore, the most effective angle were determined from the equation as follows:

$\begin{array}{lccccccr}\text { Shore length, in miles } & 0.01 & 0.1 & 1 & 10 & 14 & 53 & 10 \\ \text { Most effective angle } & 4^{\circ} & 6^{\circ} & 13^{\circ} & 27^{\circ} & 30^{\circ} & 45^{\circ} & 5\end{array}$

The above relationship shows that along the shore just downdrift of a barrier, the most effective waves are those hitting the shore with their crests almost parallel to the shore. It is believed that such nearly direct waves and not the rip currents are the cause of the erosion at the downdrift side of a barrier. Going downdrift along the shore, the most effective angle increases until at a distance of about 14 miles it reaches $30^{\circ}$. This angle was also obtained in the model tests by Johnson and might be of help in determining the scale for that. model. The most effective angle of $45^{\circ}$ corresponds to a shore-line length of 53 miles. However, this distance was derived from the transport equation for the Great Lakes and cannot be transferred directly to ocean conditions. For a very long straight reach, the angle should be close to $90^{\circ}$, the angle observed by Munch-Petersen. Also in shorter reaches the maximum transport can be produced by waves moving parallel to shore when the downdrift portion of a convex beach is parallel to the direction of the wind.

\section{Shore length and transport.}

The Beach Erosion Board, Corps of Engineers, as reported by Savage, 1959, made model tests where the transport rates were compared for two different shore lengths with all other factors remaining unchanged. In the first series of tests the beach length was about 97 feet, and in the second series the same beach was divided into two reaches by a long, high groin as shown in Figure 10. The effective length of the beach downdrift of the groin was 34 feet. The rate of transport was measured at the end of the original long and subsequent short beaches. The average transport rates during the 50 hours of testing were 374 pounds per hour for the 97-foot beach, and 154 pounds per hour for the 34-foot beach.

It is not possible to compare the model transport rates directly with those observed in the Great Iakes because of the uncertainty of the model scale. However, both the model tests and the actual transport data from the Great lakes show that the unobstructed shore length is an important factor affecting the quantity of transport. The tests in the model were made with an angle of $30^{\circ}$ between the wave crests and the shore If this angle was the most effective angle for that model then, as shown 


\section{LITTORAL TRANSPORT IN THE GREAT LAKES}

above, the corresponding long and short shore lengths in the Great Lakes would be in the order of 14 and 4.9 miles, respectively. The ratio between the computed transports for these long and short shore lengths in the Great Iakes is 2.41, and the ratio of the corresponding transports observed in the model is 2.43 .

Wave-crest angle and transport.

As previously shown, at any point along the shore there is one wave direction which produces the maximum transport, and lesser amounts of transport are produced with the same energy from different wave directions. The variation of transport with changing wave angles was investigated in model tests by Johnson. The relationship between the angle of wave crests and per cent of maximum transport determined in the model and as computed for comparable conditions in the Great Lakes are shown in Figure II. A wave steepness of 0.04 from model tests was selected for computing the transport. This wave steepness occurs during the larger storms on the Great Lakes. The transports observed in the model and computed by equation are in good agreement for wave angles around $30^{\circ}$, but deviate as the angle increases and decreases. One reason for the deviations probably is that the effective shore length of the model is not constant, but changes with the angle of the wave machines.

\section{ACCRETION IN FRONT OF A BARRIER}

When a barrier which would stop the littoral transport is planned, it is necessary to estimate the effects of the structure. Normally, an accretion of the drift will take place on the updrift side of the barrier, and an erosion of a larger or lesser extent will occur on the downdrift side. The accretion over a number of years is the sum of the annual transports less the erosion from the face of the deposits by waves from the downdrift direction. The erosion from the deposits is equal to the transport originating along the face of the deposits.

The accretion will occur within the triangle formed by the natural shore, the barrier, and the new shore as shown in Figure 12. Two sides of the triangle are known, but the new shoreline must be estimated. The concave shape of the new shore-line is more or less defined by two tangents. The angle between the new and natural shore, lines, $\alpha_{1}$, may be estimated by assuming that the transport would move along the tangent at this angle without depositing or picking up new material. Under these conditions, the transport would be equal to $19 \mathrm{E}_{0} \sin \left(\alpha_{0}-\alpha_{1}\right)$. Equating this transport to the actual transport at the point of intersection of the new and natural shore-Iines gives a relationship between $\alpha_{1}$ and the updrift shore length as follows:

$$
\sin \left(\alpha_{0}-\alpha_{1}\right)=\left(1-e^{-0.023 D \cot \alpha_{0}}\right) \sin \alpha_{0}
$$

Equation (II) shows that the angle between the new and natural shore-lines will be small for long updrift shore length, and approaches the angle of the wave crests as the updrift shore length becomes very short. 


\section{COASTAL ENGINEERING}

The angle of the tangent at the barrier end of the new shore-line, $\alpha_{2}$, is always less than the angle of the wave crests $\alpha_{0}$. It would be equal to $\alpha_{0}$ if there were no energy losses in the movement of the drift.

The values of the angles of the new shore tangents discussed above were based on a consideration of some of the theoretical factors involved in the problem of accretion. These limits are considerably modified by other factors such as the increasing storage capacity due to the progressively deeper water out from the natural shore, and that some displacement of the material deposited with one wave direction takes place when the direction changes and also by wave reflections from the barrier. Therefore the angles of the new shore tangents derived above must be modified by observed data.

In most cases the angle between the mean new shore-line and the natural shore-line, angle $\beta$ in Figure 12, can be estimated with sufficient accuracy by applying an experience factor to the mean of the wave-crest angles weighted to their transport. The equation to estimate the angle $\beta$ is

$$
\beta=x \frac{\alpha_{01} Q_{1}+\alpha_{02} Q_{2}+\alpha_{03} Q_{3}+\ldots}{Q_{1}+Q_{2}+Q_{3}+\ldots}
$$

where

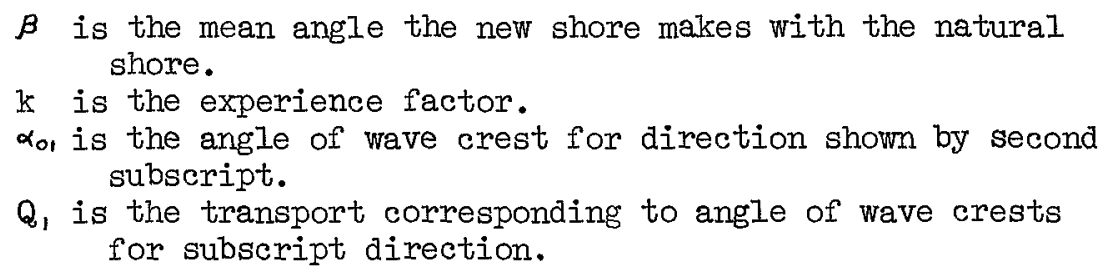

The value of $k$ obtained from observed data from Grand Marais and Fairport was found to be 0.33 . The value of $k$ determined from the Beach Erosion Board model tests illustrated in Figure 10 is 0.5 for waves approaching from a single direction at an angle of $30^{\circ}$.

\section{PROBLEM OF EROSION}

Although the problem of erosion is not the subject of this paper, some observations are being added for future studies. Because a barrier stops the littoral transport, the waves have a larger energy to pick up new material from the shore on the downdrift side of the barrier, and erosion of the shore takes place. Observations show that the volume eroded from the shore is usually much greater than the transport requiremer A portion of this eroded material is transported along the shore but a larger portion is used to change the profile of the beach. Observations at Grand Marais and Fairport indicate that a flattening of the profile occurs. The eroded material is transported some distance downdrift and deposited ir the deeper places. Sooner or later the beach is changed so much that a ner eauilibrium is established, and subsequent erosion is just enough to satis. the needs of transport. 


\section{LITTORAL TRANSPORT IN THE GREAT LAKES}

The profiles on the east side of Grand Marais Harbor (Fig. 4) show a large erosion between 1867 and 1902, but much smaller erosion during the 1902-1941 period. In the Alabaster reach in Lake Huron, where the erosion is not man-induced and the process has been going on for centuries, the profiles shown in Figure 7 indicate that the slope of the beach is already stable, and the amount of erosion is nearly equal to that needed for the littoral transport.

One must also consider the amount of drift from opposite directions being stopped on the downdrift side of a barrier. If the amount of that drift is significant, the expected erosion may not even take place, and deposition of drift material may occur on both sides of the barrier.

\section{ACKNOWLEDGMENTS}

Many of the data used in this paper were taken from a littoral transport study made by the United States Lake Survey, Corps of Engineers, United States Army. The author is greatly indebted to I. A. Hunt, Jr., Major, Corps of Engineers, at that time the District Engineer, who initiated and directed that study. His work on the relationship of overwater winds with overland winds and on wave energy created a firm basis for the present paper. The author gratefully acknowledges the help of two other Lake Survey engineers, Mr. J. A. Derecki who carried out the necessary calculations, and Mr. L. T. Schutze who edited the paper.

\section{REFERENCES}

Beach Erosion Board (1954). Shore protection, planning, and design: Technical Report No. 4.

Caldwell, J. M. (1956). Wave action and sand movement near Anaheim Bay, California: Beach Erosion Board, Technical Memorandum No. 68.

Hunt, I. A., Jr. (1958). Relationships between overwater wind and overland wind: Lake Erie: U. S. Lake Survey, Corps of Engineers, Detroit.

Johnson, J.W. (1953). Sand transport by littoral currents: Proceedings of the Fifth Hydraulics Conference.

Lee, C. E. (1954). Filling pattern of the Fort Sheridan Groin System: Proceedings of Fourth Conference on Coastal Engineering.

Savage, R. P. (1959). Laboratory study of the effect of groins on the rate of littoral transport: equipment development and initial tests: Beach Erosion Board, Technical Memorandum No. 114 .

Svendsen, S. (1950). Munch-Petersen's littoral drift formula: Bulletin of the Beach Erosion Board, Vol. 4, No. 4.

Zumberge, J. H. and Wilson, J. T. (1954). Effect of ice on shore development: Proceedings of Fourth Conference on Coastal Engineering. 